\title{
THE EFFECT OF DISACCHARIDE CONCENTRATION IN A LIQUID BINDER ON THE MECHANISMS AND KINETICS OF DISC GRANULATION
}

\author{
Andrzej Obraniak ${ }^{1}$, Tadeusz Gluba ${ }^{2 *}$ \\ ${ }^{1}$ Lodz University of Technology, Faculty of Process and Environmental Engineering, Wolczanska \\ 213, 90-924 Lodz \\ ${ }^{2}$ Lodz University of Technology, Faculty of Biotechnology and Food Sciences, Wolczanska 173, \\ 90-924 Lodz
}

Analysis of granulation kinetics was carried out using a laboratory disc granulator with a diameter $D$ of $0.5 \mathrm{~m}$. A liquid binder was delivered to the tumbling bed at a constant flow rate with a nozzle generating droplets with a size of approx. 4-5 mm. Fine-grained chalk was used as a model of raw material and water or disaccharide solution with concentrations of $20-40 \%$ as a wetting liquid. Different times of droplet delivery ranging from 2 to $6 \mathrm{~min}$ were utilized. Granulometric composition of the bed for selected lengths of process, bed moisture and the moisture of individual size-fractions were assessed. Mass of granulated material, which was transferred from nuclei fraction to other size fractions was determined on the basis of mass balance analysis and the assessment of liquid migration between fractions. The influence of disaccharide concentration in wetting liquid on the aforementioned phenomena was also examined.

Keywords: disc granulation, kinetics, disaccharide solution

\section{INTRODUCTION}

Kinetics of tumble granulation depends mainly on the prevailing mechanisms of granule formation occurring during the process. Newitt and Conway-Jones (1958) and Capes and Danckwerts (1965) analysed this process and identified the following mechanisms of granulation: wetting and nucleation, layering, coalescence, consolidation as well as crushing and abrasion. The authors assumed that these mechanisms may occur independently or jointly at a given stage of the process. The use of wetting liquid in a process was a common feature of the analysed studies. The type of capillary interactions between liquid and bulk material depends on: the ratio of liquid volume and intergranular volume. Newitt-Jones and Conway (1973) identified several states of a liquid-solid material system: pendular, funicular, capillary and droplets - on the basis of liquid content.

Nucleation, during which the delivered binding liquid wets powder forming initial aggregates (nuclei) is the first step of granulation. Previous analyses of this step focused mostly on two aspects: the wettability of a solid body by a liquid binder and the conditions of liquid phase distribution in powder material. Jaiyeoba and Spring (1980) performed the aforementioned analysis of a mixture of three powders. Gluba et al. (1990) examined the influence of conditions of selected powder material wetting on the parameters of particle size distribution of granules formed during the process of wet drum granulation. The parameters of granulometric composition of products obtained from particular materials were linked with their wettability expressed as so-called aspiration potential. Vonk (1997) 
showed that nucleation mechanism is influenced by the quotient of droplet size and basic dimensions of powder particles. Schaefer and Mathiesen (1996) proposed two different mechanisms of nucleation, depending on the relative size of droplets and raw material particles: distribution mechanism and immersion mechanism. The aforementioned mechanisms describing granulation process have been extended to wet granulation in high-speed mixers by Scott et al. (2000). Analysis of the influence of wetting liquid properties on the granulation process shows also the impact of viscosity on nucleation kinetics. Viscous binders, despite being difficult to distribute, may modify the mechanisms of nucleation (Hoornaert et al., 1998), which in many cases improves process conditions. Schaafsma (1998) demonstrated the association between nuclei formation with the degree of bed saturation and wetting time. A similar description of nucleation mechanism was suggested by Butensky and Hyman (1971). Le et al. (2011) have investigated the granulation mechanisms on a microscopic, single granule scale, and their effect on the uniformity of granule structure, binder content, porosity, dissolution rate and granule strength. Apart from mechanisms responsible for the increase of granule size during granulation processes, also destructive processes characteristic of grinding processes, e.g. in ball mills (Olejnik, 2013) or in pearl mills (Heim and Solecki, 2000) take place.

Pearson (1998) and Ramaker (1998) carried out analysis of granulation process with the use of coloured liquid for a more detailed examination of disintegration mechanism. Similar experiments were performed by Obraniak and Gluba (2012) and Obraniak (2017) who analysed changes in absorbance of individual fractions of granulated bed. Litster and Ennis (2004) introduced the criteria of granule disintegration on the basis of Stokes deformation number.

Ramachandran et al. (2009) presented a dynamic model for granulation process, employing a threedimensional population balance framework. They obtained a good agreement between experimental and simulation results for the granule size distribution under different operating conditions.

Previous analyses have shown that the conditions of wetting liquid delivery influence nucleation and in consequence the effect of granulation. Litster et al. (2001) defined an equipment independent parameter, dimensionless spray flux, to characterise the most important process parameters in the nucleation process: solution flow rate, powder flux, and binder drop size. Iveson et al. (2001) critically evaluated the understanding of the three key areas of wet granulation processes: wetting and nucleation, consolidation and growth, and breakage and attrition. Hapgood et al. (2003) proposed a nucleation regime map which demonstrated the interaction between drop penetration time and spray flux in nucleation. The nucleation regime map provides a rational basis for design and scale-up of nucleation and wetting in wet granulation. Hapgood et al. (2002) studied the kinetics of drop penetration by filming single drops of several different fluids as they penetrated into loosely packed beds of glass ballotini, lactose, zinc oxide and titanium dioxide powders. A new two-phase model was proposed where the total volume of macrovoids was assumed to be the difference between the bed porosity and the tap porosity. Abberger et al. (2002) used the ratio of droplet size/particle size to determine whether the mechanism of nucleation was distribution or immersion. Distribution was promoted by a low ratio, whereas immersion was promoted by a high ratio. Charles-Williams et al. (2011) carried out single drop penetration experiments into static dry and pre-wetted powder beds. They have discovered that, on porous surfaces, the infiltration rate has a greater degree of dependence, to that of spreading, on changes in viscosity. Hapgood et al. (2004) determined nuclei distribution by the dimensionless spray flux and found that the fraction of drop controlled nuclei could be calculated analytically in advance. Nguyen et al. (2009) conducted single drop nucleation experiments using a syringe and small powder bed on varying ratios of salicylic acid and lactose powders to study the kinetics of drop penetration. They stated that the drop penetration time increased as the proportion of hydrophobic component increased in the powder mixture. Smirani-Khayati et al. (2009) used a new binder liquid distribution coefficient to characterise binder liquid distribution. They discussed the relationships between binder liquid distribution coefficient and granule size distribution. Wauters et al. (2002b) examined the 
influence of the nozzle pressure and the distance from the nozzle to the powder bed on the growth behaviour of granules as well as on the binder distribution.

Knight (1983) in his experiments added wetting liquid to calcium carbonate powder in a high shear mixer in three different ways. The method of binder delivery affected both the initial distribution of nucleus sizes and the subsequent growth of granules. Similar experiments with the same materials and devices were performed by Scott (2000). Schaefer and Mathiesen (1996) confirmed that the increase in binder particle size was associated with the increase in initial size of nuclei and with the subsequent growth rate of granules. The uniformity of binder distribution deteriorates with an increase in its viscosity, which results in a broad or even bimodal distribution of granule size. Wauters et al. (2002) studied the growth in drum granulation of particles which were pre-wetted by kneading in a plastic bag. Pre-wetting and uniform distribution of a binder in powder allowed to obtain a narrow distribution of agglomerate sizes. Also, the correlation between droplet size and the distribution of nucleus sizes in fluid bed granulators was demonstrated. According to Waldie (1991) one droplet usually tends to form one nucleus, and the size of formed granule is larger than droplet size. The intensity of liquid binder delivery is one of the most widely studied variable parameters influencing binder distribution. Rankell (1964) proved that the initial rate of nucleation increased along with increasing intensity of wetting.

Despite a wide range of studies on the mechanisms of granulation and the impact of liquid binder properties on the process, still there is no universal model concerning the discussed issues. These studies usually concern specific systems: liquid - raw powder material and are limited by the scope of used apparatus - process parameters. Moreover, there are no models which allow not only for qualitative analysis but also for a quantitative estimation of the prevalence of individual granulation mechanisms. An important utilitarian issue related with the obtaining of durable granules which would meet the requirement of clients is the selection of appropriate binding liquid used in the granulation process. In case of many fine-grained materials (e.g. limestone, dolomite and chalk powder) the use of water as binding liquid does not allow to obtain products with desired strength properties. For that reason, it is necessary to use other binders e.g. aqueous solutions of sugars, which increases the cost of granulate production. Therefore, the optimisation of disaccharide content in binding liquid is necessary.

This paper suggests a model that enables quantitative analysis of agglomeration mechanisms and determines the influence of disaccharide content in liquid binder on the kinetics of disc granulation of chalk.

\section{PURPOSE OF THE STUDY}

The aim of the study was to:

- determine the effect of disaccharide concentration in the liquid binder on granulation mechanisms and the kinetics of disc granulation,

- develop and validate methods for the quantitative assessment of nucleation and granule build-up mechanisms in disc granulation process with the method of liquid mass balance analysis in individual fractions of a semi-product,

- determine the effect of wetting liquid parameters on the size of nuclei formed during granulation,

- analyse conditions of bed moistening with monodisperse drops of liquid binder in respect to the distribution of formed nuclei size and grain composition in granulate.

\section{APPARATUS AND SCOPE OF THE STUDY}

Studies were carried out in a disc granulator schematically shown in Fig. 1. 


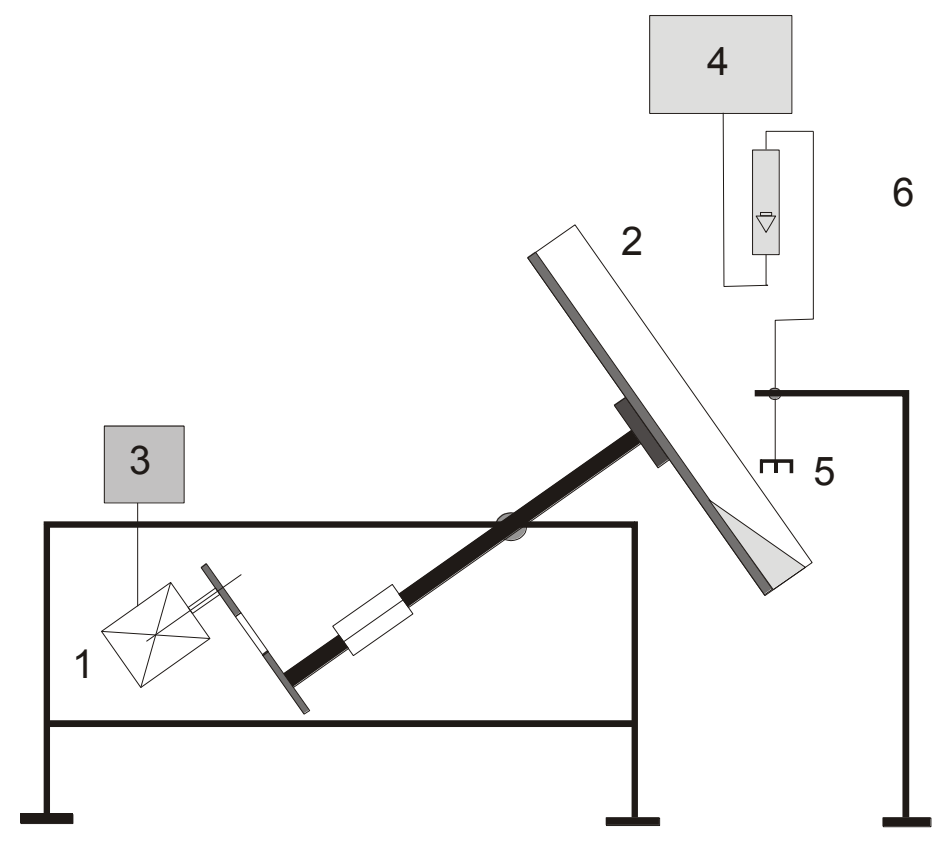

Fig. 1. The scheme of laboratory stand - disc granulator with liquid binder dosing system;

1 - electric engine, 2 - granulating disc, 3 - inverter, 4 - tank, 5 - hydraulic sprinkler, 6 - rotameter

A plate of disc granulator (2) with a diameter $D=0.5 \mathrm{~m}$, and band height $h=0.08 \mathrm{~m}$, mounted on a shaft connected with an electric motor (1) via belt transmission was the main part of the laboratory stand. Disc rotational speed was changed with an inverter (3). Liquid binder was delivered to a bed circulating at the plate from a reservoir (4) mounted at a height of $2.5 \mathrm{~m}$ through a hydraulic sprinkler (5) which provided the outflow of liquid in the form of droplets. Constant liquid pressure during the analysis was maintained by the control of its stable level in a tank.

Chalk produced by Lhoist Bukowa lime plant, with a grain size of less than $0.2 \mathrm{~mm}$ was used as a model material in granulation analysis. Water and aqueous solutions of disaccharide (food sugar) at a concentration of $20 \%, 25 \%, 30 \%, 35 \%, 40 \%$ were used as liquid binders.

\section{METHODOLOGY AND THE SCOPE OF STUDY}

Granulated bed was wetted during tumbling with water or five aqueous solutions with different concentrations of sugar. The granulation process was carried out at the time of bed wetting. The duration of each test was equal to the wetting time. After a specified time of liquid binder delivery $(2,3,4,5$ or 6 minutes) granulometric composition of the formed bed was analysed. This method of conducting experiments allowed to compare granulation effects in subsequent tests. These comparisons concerned the course of the process, the type of bed movement, and the resulting effects for the same granulation times.

Basic apparatus and process parameters including the mass of raw material, mass flow rate of wetting liquid delivery and rotational speed of the plate were determined during preliminary analysis. The angle of plate axis inclination from the horizontal axis was set to be $\alpha=45^{\circ}$ and the rotational speed of the plate was $n=14 \mathrm{~min}^{-1}$. The optimum mass of fine raw material placed on a plate was $m_{s}=1500 \mathrm{~g}$ for this setting. Mass flow rate of liquid binder delivery $q=22.5 \mathrm{~g} / \mathrm{min}$ was applied, which allowed to obtain the outflow of each solution concentration from the nozzles in form of droplets. The liquid was delivered to the bed in such a way that droplets always fell on a dry material to eliminate the phenomenon of solid particle coalescence. Bed circulating in the granulator was moistened with drops of $4-5 \mathrm{~mm}$. Droplets of such size were obtained with the gravitational liquid delivery method through 
a uniform atomiser. The purpose of the method of wetting was to obtain a monodisperse fraction of granulated nuclei whose size would be closely related to the constant diameter of droplets. The size of droplets that initiated the granulation was determined on the basis of volume of a certain number of liquid droplets delivered to the measuring cylinder, assuming that their shape is spherical.

The product obtained was subjected to particle size analysis performed with a set of sieves with mesh sizes: $1.0-12.5 \mathrm{~mm}$. Each of the obtained size fractions was weighed on a laboratory scale and then dried at $100{ }^{\circ} \mathrm{C}$ for $24 \mathrm{~h}$. After drying, each fraction was re-weighed in order to determine its moisture and the mass of water accumulated in it.

\section{MODEL}

The assumptions used during the formulation of the model are associated with droplet manner of bed wetting and the site of liquid delivery to the bed. It was assumed that:

1. Droplets of sizes between 4 and $5 \mathrm{~mm}$ after falling on the dry powder material form nuclei in which the whole delivered liquid is accumulated.

2. Liquid droplets always fall on a non-granulated raw material thus eliminating the phenomenon of solid particle coalescence.

3. The migration of liquid binder to other size fractions occurs only as a result of transfer of abraded or crumbled pieces of wet material nuclei.

4. Moisture of abraded and crushed fragments of nuclei is the same as the moisture of nuclei.

5. The transfer of wet loose material to other size fractions and the accompanying migration of liquid are the result of the following granulation mechanisms:

a) abrasion of nuclei - migration to smaller factions,

b) crushing of nuclei - migration to smaller factions,

c) layering of nuclei - migration to larger factions.

The following process parameters and parameters measured after the end of wetting were assumed to be known:

- Liquid concentration - $c$

- Mass of each wet and dry material size fraction " $j$ " for particular times of wetting $t_{i}: m_{j}\left(t_{i}\right), M_{j}\left(t_{j}\right)$

- Mass of water contained in each fraction " $j "$, moisture of " $j$ " fraction in time $t_{i}: M^{W}{ }_{j}\left(t_{i}\right), w_{j}\left(t_{i}\right)$

Ad a) The mass of dry material transferred from nuclei fraction to $0-1 \mathrm{~mm}$ size fraction as a result of abrasion can be calculated from Eq. (1) after transforming the formula defining moisture content in the abrades:

$$
M_{0-1}^{a b r}\left(t_{i}\right)=\frac{M_{0-1}^{w}\left(t_{i}\right)}{w_{\text {nucl }}\left(t_{i}\right)}
$$

Dry mass of the abraded material calculated using Eq. (1) contains the mass of transferred bulk material and the mass of sugar contained in a liquid accumulated in $(0-1)$ size fraction. Sugar mass can be computed from Eq. (2).

$$
M_{0-1}^{\text {sug. }}\left(t_{i}\right)=\frac{c \cdot M_{0-1}^{w}\left(t_{i}\right)}{1-c}
$$

$A d b$ ) Mass of material transferred as a result of crushing from nuclei fraction to any other ,,$j$ " fraction in the range of $1-4 \mathrm{~mm}$ is calculated using Eq. (3) and sugar mass is computed in the same manner from Eq. (2). 


$$
M_{j}^{c}\left(t_{i}\right)=\frac{M_{j}^{w}\left(t_{i}\right)}{w_{\text {nucl }}\left(t_{i}\right)}
$$

$A d c$ ) Mass transferred from nucleus fraction to granule fraction:

Mass of granule fraction determined on the basis of sieve analysis contains the mass of nuclei which after the attachment of bulk or abraded material increased their diameter as a result of layering. If the aforementioned increase in dimensions is due to the adherence of wet material from previously abraded nuclei, then the moisture of granule fraction will be approximately the same as the moisture of nuclei. If the moisture of formed granules is lower than that of nuclei it means that dry raw material was additionally attached to granules. The mass of nucleus fraction $M_{\text {g.nucl, }}^{o}$ which after $t_{i}$ time co-forms granule fraction was calculated from Eq. (4).

$$
M_{\text {g.nucl. }}^{o}\left(t_{i}\right)=\frac{M_{g}^{w}\left(t_{i}\right)}{w_{\text {nucl }}\left(t_{i}\right)}
$$

\section{EXPERIMENTAL RESULTS}

On the basis of the obtained results, associations reflecting changes in granulometric composition of processed bed after a specified time of wetting have been prepared. The results of a sieve analysis demonstrate the dominant portion of $6.3-8 \mathrm{~mm}$ size fraction and adjacent fractions in the formed granulate in case of all times of wetting. It is directly associated with bed wetting manner and the size of sprayed droplets of liquid $(4-5 \mathrm{~mm}$ ). Such a delivery of liquid to bulk material promotes, in the presented range of parameters and in case of a given material, the formation of granulation nuclei which produce $6-8 \mathrm{~mm}$ agglomerates (larger than the size of delivered droplets). This trend is consistent with the results of other studies (Schaafsma et al., 1998; Waldie, 1991).

Figures 2, 3, 5 present a comparison of mass content of individual size fractions obtained using different process parameters. The analysis of the obtained results reveals a relatively small content of $1-4 \mathrm{~mm}$ fraction which, taking into account the wetting method, does not constitute the nucleus fraction with smallest sizes.

Observations of droplet wetting phenomenon both during granulation and preliminary analysis ruled out the possibility that droplets broke into smaller pieces while falling from the height of a mounted nozzle tip and resulting in formation of nuclei of smaller diameters. These fractions are formed as a result of nucleus crushing. There is also the possibility that the raw material adheres to wet, crumbled part of nuclei. Also, the mass content of a $10-12.5 \mathrm{~mm}$ fraction is small, which can be explained by a hindered build-up of surface dry agglomerates and the lack of conditions to coalesce. This fraction, and probably also a part of $8-10 \mathrm{~mm}$ fraction composes of granules formed from nuclei which attached material from $0-1 \mathrm{~mm}$ size fraction through layering and thus enlarging their dimensions.

Figure 4 presents sample change of the mass of water accumulated in individual size fractions between various wetting times. The comparison of results which is shown in Figs. 3, 4 and 5 allows for a more comprehensive analysis of the impact of various granulation mechanisms on granulometric composition of obtained granules. Similar distribution and the nature of changes in bed properties can be observed in case of various wetting times. 


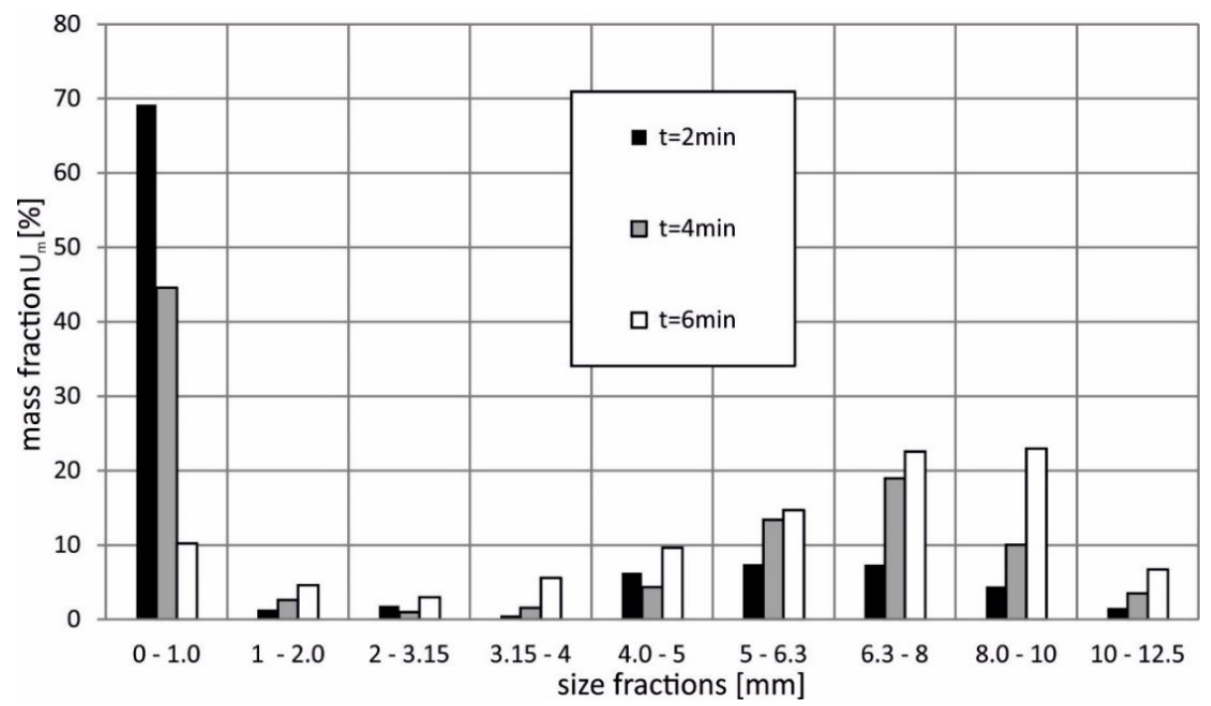

Fig. 2. The comparison of mass content of granulated bed between three various times of wetting (the concentration of wetting liquid $c=25 \%$ )

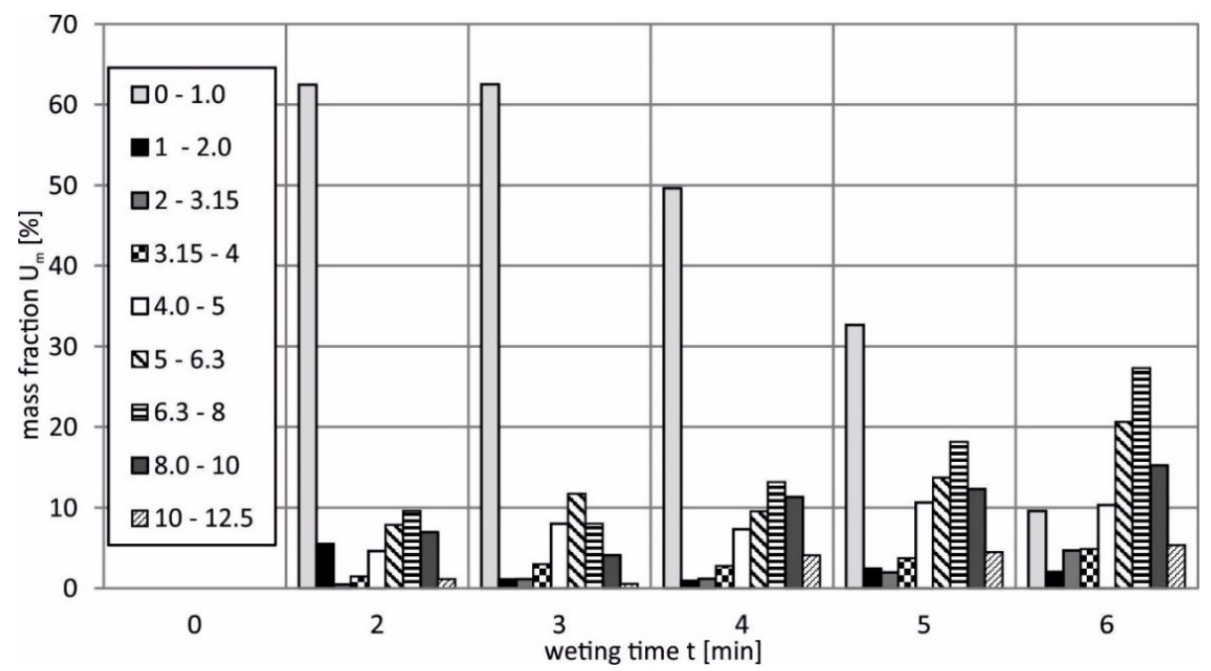

Fig. 3. Sample change in mass content of granulated bed during the process of wetting with liquid with a concentration $c=40 \%$

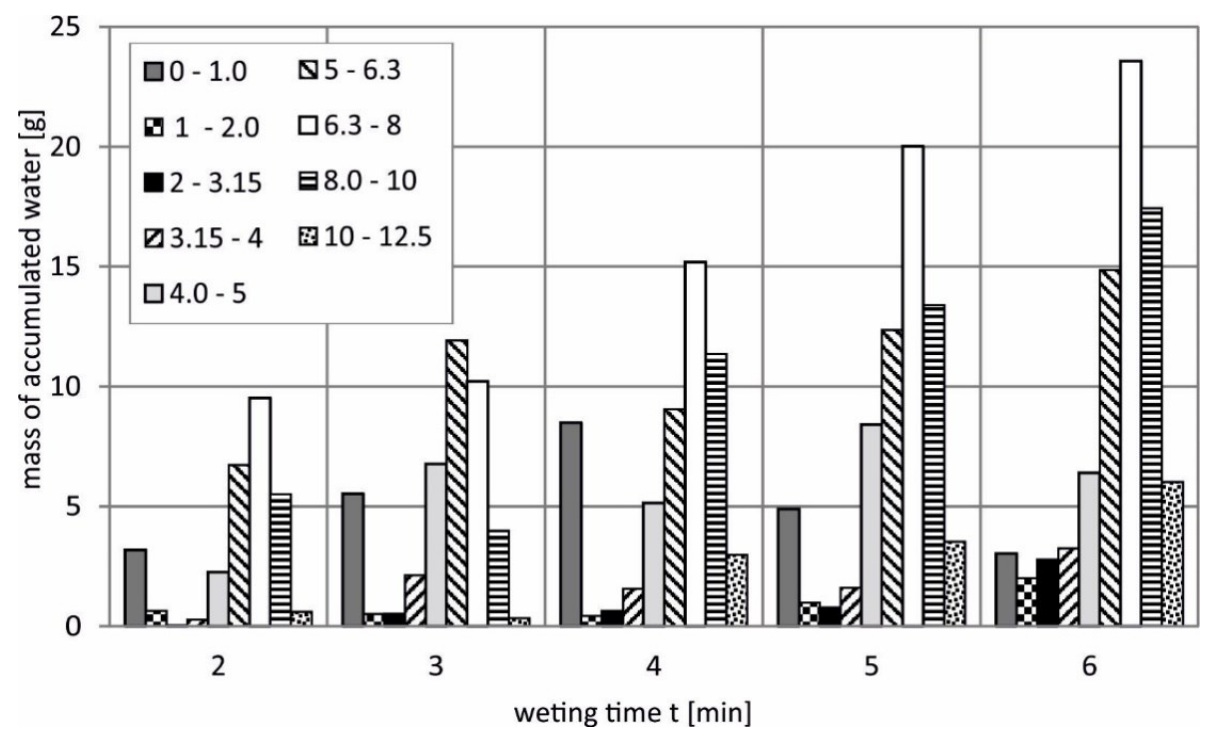

Fig. 4. Sample change in the mass of water accumulated in particular fractions of granulated bed during the process of wetting with liquid with a concentration $c=40 \%$ 


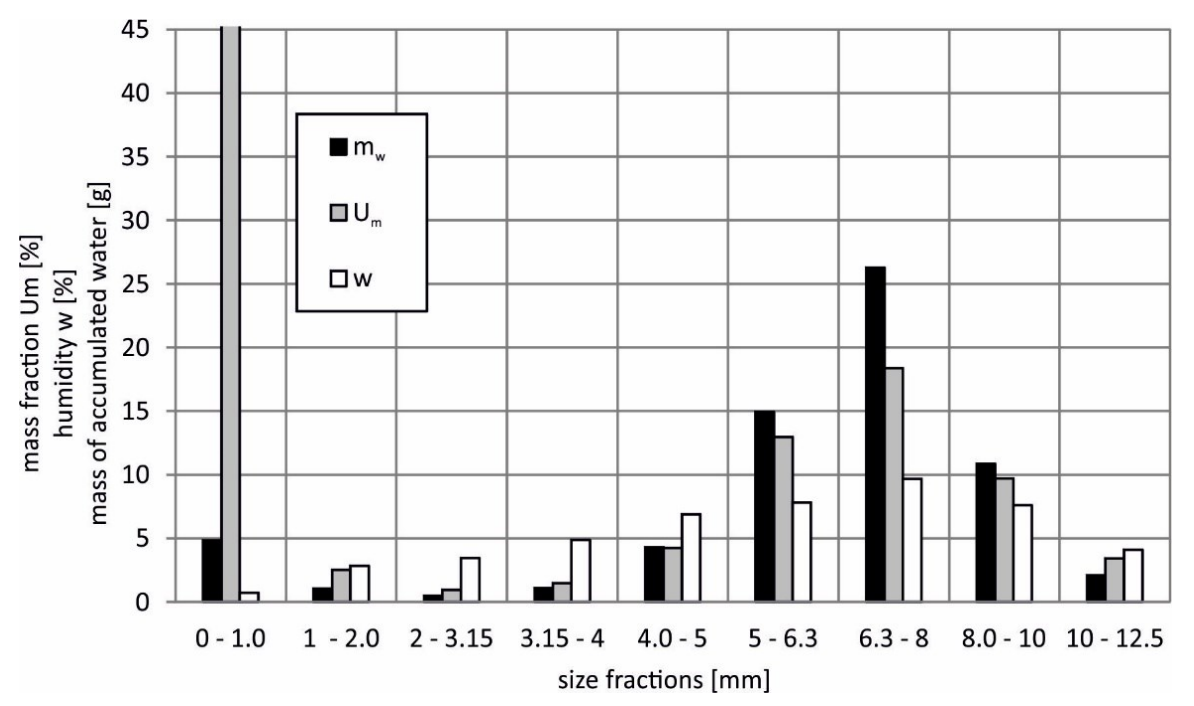

Fig. 5. The comparison of sample changes in mass content, moisture, and the mass of accumulated water in individual fractions of granulated bed during the process of wetting with liquid with the concentration

$$
c=25 \%,(t=4 \mathrm{~min})
$$

The analysis of graphs confirms the assumptions made during model preparation and leads to the conclusion that changes in water mass in individual size fractions as well as changes in moisture of these fractions can be indicators for a qualitative and quantitative evaluation of granulation mechanisms responsible for the transfer of material mass between various factions of formed granulate. The obtained results allow for the assessment of the nature of changes in the content of fractions, nuclei and granules, and also for the comparison of the range of two disintegration phenomena, i.e. crushing and abrasion.

On the basis of the obtained results, it can be concluded that the extent of abrasion of the wet material from the surface of nuclei and granules may be smaller than the extent of their crushing. This suggestion is confirmed by a higher total mass of accumulated water in fractions $1-4$ than that in fractions $0-1$. This phenomenon is disadvantageous in the context of required product homogeneity, especially due to the fact that the probability of the attachment of wet abraded material to previously formed agglomerates is greater than the possibility of the attachment of small fragments constituting $1-4 \mathrm{~mm}$ size fraction because of their size. Moreover, agglomerates formed from small fragments (crumbs) are characterised by a lower strength.

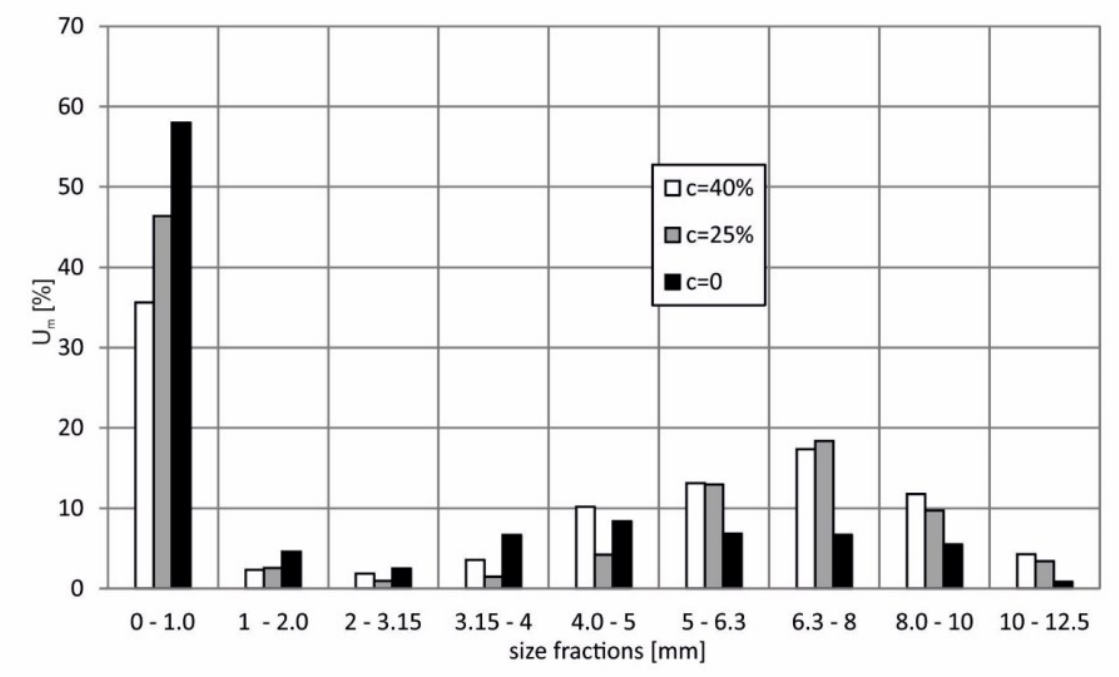

Fig. 6. The impact of the concentration of wetting liquid solution on mass content of size fractions (bed moisture $w=4.4 \%$ ) 
Figure 6 presents the comparison of mass contents of bed fractions for selected concentrations of wetting liquid. This paper provides also analysis of impact of wetting liquid concentration on the formation and properties of nuclei. The obtained results indicate that an increase in sugar content in a solution positively affects granulation process. Figure 6 shows that for the specified moisture content $(w=4.4 \%)$, the share of the finest fractions comprising non-granulated material and created abraded material decreases along with an increase in the concentration of wetting liquid. This observation confirms beneficial impact of disaccharide content in a solution on the rate of granule formation (approx. $2 / 3$ of the total bed mass became granulated) and on the increased resistance to abrasion of formed agglomerates.

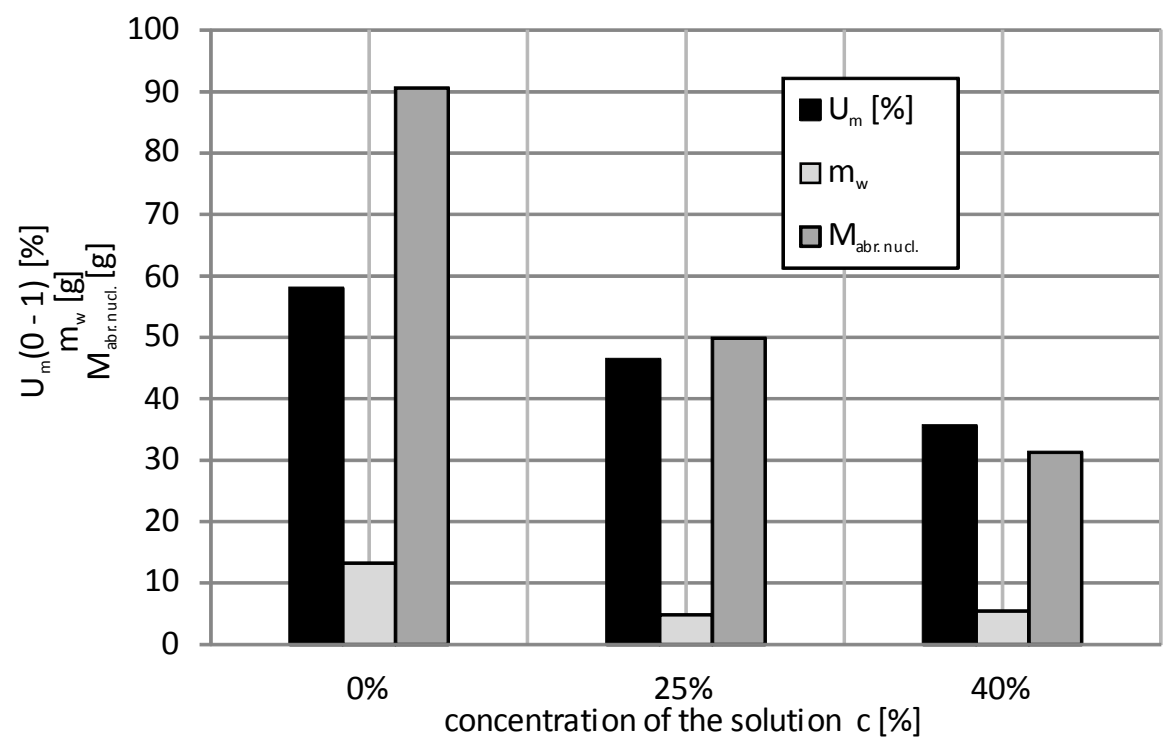

Fig. 7. The impact of wetting liquid concentration on mass content of fraction $(0-1)$, mass of water accumulated in this fraction and the mass of nuclei which underwent the abrasion process

The aforementioned conclusions are confirmed by the results of sample analysis presented in Fig. 7. This graphic contain the comparison of mass content of fraction $(0-1)$, the mass of liquid accumulated in this fraction and the mass of fine material which was abraded from the fraction of nuclei $M_{a b r . n u c l .}$ and adhered to fraction $(0-1)$. This comparison was performed for different concentrations of the wetting solution. The mass of abraded nuclei was calculated from the model in Eq. (1). The obtained results show that application of disaccharide solution not only accelerates the granulation process, but also results in the formation of agglomerates that are more resistant to abrasion. This conclusion is confirmed by much smaller mass of abraded material adhered to fraction $(0-1)$ in experiments carried out with disaccharide as a wetting solution in comparison to experiments when using water. Obtaining a satisfactory granulation results despite using much lower bed moisture is another benefit of the application of disaccharide as wetting solution. This allows for significant savings during drying of a product which is additionally enriched with organic ingredients.

\section{CONCLUSIONS}

- The use of water solution of disaccharide as wetting liquid positively influences the kinetics of disc granulation.

- Bed wetted with disaccharide solution is more resistant to abrasion and granulation process is faster and requires less moisture.

- The proposed model allows for qualitative and quantitative analysis of granulation mechanisms occurring during bed wetting. 
- The course of nucleation assumed in this model was confirmed in the analysis of disc granulation.

- The obtained results confirmed the assumed mechanism of water migration from nucleus fraction towards other size fractions, which is based on the transfer of liquid to other size fractions together with wet material.

- The phenomenon of disintegration of nucleus and granule fractions is the driving force behind the formation of fractions with sizes of $1-4 \mathrm{~mm}$.

- Agglomerates formed as a result of crushing of nuclei and granules can increase their mass by attaching the surrounding material abraded from other size fractions and dry raw material (layering).

- Bed wetting with monodisperse drops of binding liquid does not result in the formation of a monodisperse product with granular size resulting from the multiplicity of droplets although the proportion of this granule fraction is dominant for all process times.

The work was carried out under research projects no. 501/10-34-1-7015 and 501/15-30-1-9156.

\section{SYMBOLS}

$c \quad$ liquid concentration, $\mathrm{kg}$ of sugar $/ \mathrm{kg}$ of solution

$M_{\text {abr.nucl }} \quad$ mass of fine material which was abraded from the fraction of nuclei, $g$

$M_{0-1}^{a b r}\left(t_{i}\right) \quad$ mass of dry material transferred from nucleus fraction to $0-1 \mathrm{~mm}$ size fraction as a result of abrasion, $g$

$M_{\text {g.nucl. }}^{o}\left(t_{i}\right)$ mass of nucleus fraction, which after $t_{i}$ time co-forms granule fraction, $\mathrm{g}$

$M_{g}^{w}\left(t_{i}\right) \quad$ mass of water contained in granule fraction for particular times of wetting $t_{i}, \mathrm{~g}$

$m_{j}\left(t_{i}\right) \quad$ mass of each wet material size fraction " $j$ " for particular times of wetting $t_{i}, \mathrm{~g}$

$M_{j}\left(t_{j}\right) \quad$ mass of each dry material size fraction " $j$ " for particular times of wetting $t_{i}, \mathrm{~g}$

$M_{j}^{c}\left(t_{i}\right) \quad$ mass of material transferred as a result of crushing from nuclei fraction to any other,$j$ " fraction, $g$

$M_{j}^{w}\left(t_{i}\right) \quad$ mass of water contained in each fraction " $j "$, in time $t_{i}, \mathrm{~g}$

$m_{s} \quad$ mass of fine raw material, $\mathrm{g}$

$M_{0-1}^{\text {sug. }}\left(t_{i}\right) \quad$ mass of sugar contained in a liquid accumulated in $(0-1)$ size fraction, $g$

$n \quad$ rotational speed of the plate, $\min ^{-1}$

$q \quad$ mass flow rate of liquid binder delivery, $\mathrm{g} / \mathrm{min}$

$t \quad$ wetting time, min

$U_{m} \quad$ mass fraction, \%

$w_{j}\left(t_{i}\right) \quad$ moisture of " $j "$ fraction in time $t_{i}$

$w_{\text {nucl }}\left(t_{i}\right) \quad$ moisture of nuclei fraction after " $i$ " time of wetting $t_{i}, \mathrm{~kg}$ of water $/ \mathrm{kg}$ dry material

$\alpha \quad$ the angle of plate axis inclination

\section{REFERENCES}

Abberger T., Seo A., Schaefer T., 2002. The effect of droplet size and powder particle size on the mechanisms of nucleation and growth in fluid bed melt agglomeration. Int. J. Pharm., 249, 185-197. DOI: 10.1016/S03785173(02)00530-6.

Butensky M., Hyman D., 1971. Rotary drum granulation. An experimental study of the factors affecting granule size. Ind. Eng. Chem. Fundam., 10, 212-219. DOI:10.1021/1160038a005. 
Capes C.E., Danckwerts P.V., 1965. Granule formation by the agglomeration of damp powders: Part 1. The mechanism of granule growth. Trans. Inst. Chem. Eng., 43, 116-124.

Charles-Williams H.R., Wengeler R., Flore K., Feise H., Hounslow M.J., Salman A.D., 2011, Granule nucleation and growth: Competing drop spreading and infiltration processes. Powder Technol., 206, 63-71. DOI: 10.1016/j.powtec.2010.06.013.

Gluba T., Heim A., Kochanski B. 1990. Application of the theory of moments in the estimation of powder granulation of different wettabilities. Powder Handling and Processing, 2, 323-326.

Hapgood K.P., Litster J.D., Biggs S.R., Howes T., 2002. Drop penetration into porous powder beds. J. Colloid Interface Sci., 253, 353-366. DOI: 10.1006/jcis.2002.8527.

Hapgood K.P., Litster J.D., Smith R., 2003. Nucleation regime map for liquid bound granules. AIChE J., 49, 350361. DOI: 10.1002/aic.690490207.

Hapgood K.P., Litster J.D., White E.T., Mort P.R., Jones D.G., 2004. Dimensionless spray flux in wet granulation: Monte Carlo simulations and experimental validation. Powder Technol. 141, 20-30. DOI: 10.1016/j.powtec.2004.02.005.

Heim A., Solecki M., 2000. Dezintegracja komórek mikroorganizmów w przepływowych młynach mieszalnikowych. Inż. Chem. Proces., 21, 311-327.

Hoornaert F., Wauters P.A.L., Meesters G.M.H., Pratsinis S.E., Scarlett B., 1998. Agglomeration behaviour of powders in a Lödige mixer granulator. Powder Technol., 96, 116-128. DOI: 10.1016/S0032-5910(97)03364-0.

Iveson S.M., Litster J.D., Hapgood K.P., Ennis B.J., 2001. Nucleation, growth and breakage phenomena in agitated wet granulation processes: A review. Powder Technol., 117, 3-39. DOI: 10.1016/S00325910(01)00313-8.

Jaiyeoba K.T.,. Spring M.S, 1980. The granulation of ternary mixtures: The effect of the wettability of the powders. J. Pharm. Pharmacol., 32, 386-388. DOI: 10.1111/j.2042-7158.1980.tb12948.x.

Knight P.C., Instone T., Pearson J.M.K., Hounslow M.J., 1998. An investigation into the kinetics of liquid distribution and growth in high shear mixer agglomeration. Powder Technol., 97, 246-257. DOI: 10.1016/S0032-5910(98)00031-X.

Le P.K., Avontuur P., Hounslow M.J., Salman A.D., 2011. A microscopic study of granulation mechanisms and their effect on granule properties. Powder Technol., 206, 18-24. DOI: 10.1016/j.powtec.2010.06.014.

Litster J.D., Hapgood K.P., Michaels J.N, Sims A., Roberts M., Kameneni T., Hsu T., 2001. Liquid distribution in wet granulation: Dimensionless spray flux. Powder Technol., 114, 32-39. DOI: 10.1016/S0032-5910(00)00259$\mathrm{X}$.

Litster J.D., Ennis B.J., 2004. The science and engineering of granulation processes. Particle Technology Series. B. Scarlett, Kluwer Academic Publishers, Dordrecht, The Netherlands.

Newitt D.M., Conway-Jones J.M., 1958. A contribution to the theory and practice of granulation. Trans. I. Chem. Eng., 36, 422-441.

Nguyen T., Shen W., Hapgood K., 2009. Drop penetration time in heterogeneous powder beds. Chem. Eng. Sci., 64, 5210-5221. DOI: 10.1016/j.ces.2009.08.038.

Obraniak A., Gluba T., 2012. A model of agglomerate formation during bed wetting in the process of disk granulation. Chem. Process Eng., 33, 153-165. DOI: 10.2478/v10176-012-0014-1.

Obraniak A., 2017. Analysis of the phenomenon of nuclei mass transfer during the disc granulation. Przemyst Chemiczny, 96, 241-244. DOI: 10.15199/62.2017.1.30.

Olejnik T.P., 2013. Selected mineral materials grinding rate and its effect on product granulometric composition. Physicochem. Probl. Miner. Process., 40, 407-418. DOI: 10.5277/ppmp130203.

Pearson J.M.K., Hounslow M.J., Instone T., Knight P.C., 1998. Granulation kinetics: the confounding of particle size and age. World Congress on Particle Technology, Brighton, UK, I. Chem. E, paper 86.

Ramachandran R., Immanuel C.D., Stepanek F., Litster J.D., Doyle F.J., 2009. A mechanistic model for breakage in population balances of granulation: Theoretical kernel development and experimental validation. Chem. Eng. Res. Des., 87, 598-614. DOI: 10.1016/j.cherd.2008.11.007.

Ramaker J.S., Jelgersma M.A., Vonk P., Kossen N.W.F., 1998. Scale-down of a high shear pelletisation process: flow profile and growth kinetics. Int. J. Pharm., 166, 89-97. DOI: 10.1016/S0378-5173(98)00030-1.

Rankell A.S., Scott M.W., Lieberman H.A., Chow F.S., Battista J.V., 1964. Continuous production of tablet granulations in fluidized bed II. Operation and performance of equipment. J. Pharm. Sci., 53, 320-324. DOI: 10.1002/jps.2600530316 
Scott A.C., Hounslow M.J., Instone T., 2000. Direct evidence of heterogeneity during high-shear granulation. Powder Technol., 113, 205-213. DOI:10.1016/s0032-5910(00)00354-5.

Schaafsma S.H., Vonk P., Segers P., Kossen N.W.F., 1998. Description of agglomerate growth. Powder Technol., 97, 183-190. DOI: 10.1016/S0032-5910(97)03399-8.

Schaefer T., Wørts O., 1977. Control of fluidised bed granulation II: Estimation of droplet size of atomised binder solutions. Arch. Pharam. Chem., 5, 178-193.

Schaefer T., Mathiesen C., 1996. Melt pelletization in a high shear mixer: IX. Effects of binder particle size. Int. J. Pharm., 139, 139-148. DOI: 10.1016/0378-5173(96)04548-6.

Smirani-Khayati N., Falk V., Bardin-Monnier N., Marchal-Heussler L., 2009. Binder liquid distribution during granulation process and its relationship to granule size distribution. Powder Technol., 195, 105-112. DOI: 10.1016/j.powtec.2009.05.020.

Vonk P., Ramaker J.S., Vromans H., Kossen N.W.F., 1997. Growth mechanisms of high-shear palletisation. Int. J. Pharm., 157, 93-102. DOI: 10.1016/S0378-5173(97)00232-9.

Waldie B., 1991. Growth mechanism and the dependence of granule size on drop size in fluidised bed granulation. Chem. Eng. Sci., 46, 2781-2785. DOI: :10.1016/0009-2509(91)85147-P.

Wauters P.A.L., Van de Water R., Litster J.D., Meesters G.M.H., Scarlett B., 2002. Growth and compaction behavior of copper concentrate granules in rotating drum. Powder Technol., 124, 230-237. DOI: 10.1016/S00325910(02)00029-3.

Wauters P.A.L., Jakobsen R.B., Litster J.D., Meesters G.M.H., Scarlett B., 2002b. Liquid distribution as a means to describing the granule growth mechanism. Powder Technol.2 123, 166-177. DOI: 10.1016/S00325910(01)00446-6.

Received 15 October 2016

Received in revised form 10 May 2017

Accepted 18 May 2017 